\title{
Plasma free iron: a possible cause of oedema in kwashiorkor
}

\author{
A A Sive, W S Dempster, $\mathrm{H}$ Malan, $\mathrm{S}$ Rosseau, $\mathrm{H}$ deV Heese
}

\begin{abstract}
Background-Oedema is a sine qua non for the diagnosis of kwashiorkor yet the mechanisms leading to oedema remain ill defined.

Aims-To relate the plasma concentration of radical promoting 'free' iron to the degree of oedema in patients with kwashiorkor.

Setting-University teaching hospital.

Patients-Fifteen children with kwashiorkor, nine of whom had severe and six of whom had a moderate degree of oedema. Methods-Plasma 'free' iron was measured as bleomycin detectable iron (BDI) and related to severity of oedema and plasma albumin concentration.

Results-BDI was significantly higher in the patients with severe oedema $(20.5 v$ $6.75 \mu \mathrm{mol} / 1)$ whereas the albumin concentrations were similar ( $16 v 17 \mathrm{~g} / \mathbf{1})$. BDI was no longer present in any patients 30 days after admission.

Conclusions-'Free' circulating iron may contribute to the oedema of kwashiorkor, and its sequestration could hasten recovery and decrease morbidity and mortality. (Arch Dis Child 1997;76:54-56)
\end{abstract}

Keywords: kwashiorkor; oedema; free iron; bleomycin assay.

There is circumstantial evidence that free radicals play a part in the aetiology or pathogenesis of kwashiorkor. Our studies ${ }^{1-3}$ support the hypothesis of Golden ${ }^{4}$ that increased free radical formation and a deficiency of micronutrients essential for protective antioxidant function exists in malnourished children.

A major catalyst of free radical reactions is iron. The safe compartmentalisation of iron is critical, and should decompartmentalisation occur the Haber-Weiss and Fenton type reactions provide a mechanism for the formation of reactive oxygen species capable of reacting with and causing severe damage to cellular components. ${ }^{5}$

An assay system using bleomycin dependent degradation of DNA to measure free or loosely bound iron has been established. ${ }^{6}$ We have reported previously the detection of radical promoting iron in the plasma of $58 \%$ of children with kwashiorkor on admission to hospital and its absence in marasmic and healthy well nourished children.

The purpose of this investigation was to study children with kwashiorkor and to relate the concentration of bleomycin detectable iron (BDI) and the iron binding protein, transferrin, to the severity of oedema on admission to hospital and during their nutritional rehabilitation.

\section{Subjects and methods}

The diagnosis of kwashiorkor conformed to accepted criteria. ${ }^{7}$ Venous blood samples were collected on admission from 15 consecutive children with kwashiorkor and 24 hours, 10 days and 30 days later, during their nutritional recovery.

Before analysis plasma samples were stored in iron free polystyrene containers at $-75^{\circ} \mathrm{C}$. Precautions to eliminate contamination with extraneous additions of iron included the use of a polystyrene syringe and stainless steel needles for blood collection. Haemolysed specimens were discarded.

BDI was quantified using the basic principles developed by Gutteridge et al. ${ }^{6}$ The interassay coefficient of variation was $11.3 \%$, and validation of the assay by adding increasing amounts of ferric chloride to plasma from patients with varying iron status was as previously reported. ${ }^{1}$

Total transferrin was measured by nephelometry after reaction of the protein with specific antisera (Behring Diagnostics, Marburg, Germany) and saturation of transferrin calculated after automated analysis of plasma iron using a commercially supplied kit (BoehringerMannheim).

Nine patients were assessed as being severely oedematous and six were considered to show moderate oedema. This assessment was made by a single observer (HM) and recorded as mild $(+)$, moderate $(++)$, or severe $(+++)$. Patients with severe oedema had generalised swelling of the face and limbs. Finger pressure over the legs left an indentation of at least 0.5 $\mathrm{cm}$ in depth. Oedema was assessed as mild when pitting of the legs could just be detected, whereas patients with moderate oedema had readily detectable oedema which was intermediate between mild and severe. Each child was assessed daily from admission to day 10 by the same observer. We have previously graded the severity of kwashiorkor including the extent of oedema. ${ }^{8}$ In the 15 consecutive patients in this study none had mild oedema. Table 1 shows the age, weight, percentage of expected weight for age, height, and percentage of expected height for age of the children.

All children were fed on a commercial soya formula and a lactose free diet for 10 days. Thereafter a cows' milk containing balanced 
Table 1 Anthropometric data on admission. Patients 1-9 inclusive had severe oedema and patients 10-15 inclusive had moderate oedema

\begin{tabular}{lccllc}
\hline Patient No & Age (months) & Weight (kg) & EWFA (\%)* & Height (cm) & EHFA (\%)t \\
\hline 1 & 100 & 16.8 & 65 & 110 & 87 \\
2 & 19 & 8.3 & 75 & 77 & 95 \\
3 & 23 & 9.4 & 75 & 77.5 & 89 \\
4 & 15 & 10.5 & 94 & 74 & 93 \\
5 & 7 & 5.2 & 60 & 54 & 78 \\
6 & 21 & 9.1 & 80 & 77 & 91 \\
7 & 14 & 8.5 & 85 & 77 & 100 \\
8 & 9 & 4.4 & 51 & 57 & 80 \\
9 & 20 & 8.9 & 74 & - & - \\
10 & 17 & 7.6 & 66 & 68 & 83 \\
11 & 23 & 7.7 & 62 & 69 & 79 \\
12 & 13 & 6.4 & 60 & 60 & 78 \\
13 & 22 & 8.1 & 65 & 74 & 86 \\
14 & 9 & 7.5 & 79 & 68.5 & 95 \\
15 & 10 & 7.3 & 74 & 65 & 89 \\
\end{tabular}

^ Expected weight for age (EWFA) as a percentage of the 50th centile using National Center for Health Statistics (NCHS) standards.

† Expected height for age (EHFA) as a percentage of the 50th centile using National Center for Health Statistics (NCHS) standards.

Western style diet was introduced. The energy content of the diet increased from approximately $0.334 \mathrm{MJ} / \mathrm{kg} /$ day on admission to 0.627 $\mathrm{MJ} / \mathrm{kg} /$ day by day 10 . Patients received antibiotics for infection according to laboratory and clinical indication. All patients received additional potassium but iron was withheld until their oedema resolved.

Data were analysed using non-parametric statistics with Statistica 5.1. The MannWhitney $U$ test was used to determine differences between groups and correlation coefficients were obtained using the Spearman rank correlation coefficient.

The study was approved by the ethics and research committee of the University of Cape Town and informed consent was obtained from the custodial parent of each child.

\section{Results}

Table 2 shows the plasma concentration of BDI, transferrin, saturation of transferrin, and albumin in the nine severely oedematous patients and six with moderate oedema. BDI was higher on admission $(p=0.01)$ and at 24 hours $(p=0.02)$ in children with severe oedema than in those with moderate oedema. Albumin concentrations were not different $(p=0.17)$ between groups at admission and there was no correlation between albumin and BDI $\left(r_{\mathrm{s}}=-0.44, \mathrm{p}=0.09\right)$ or between albumin and transferrin $\left(r_{\mathrm{s}}=0.26, \mathrm{p}=0.39\right)$ on admission.

\section{Discussion}

The mechanisms responsible for oedema formation in kwashiorkor remain obscure. The notion that it is a manifestation of reduced plasma albumin secondary to low protein intake $^{9}$ has not been substantiated by later studies. The degree of oedema shows poor correlation with plasma protein concentration. ${ }^{10}$ Indeed, this study confirms the poor correlation between the plasma albumin concentration and the degree of oedema or plasma transferrin concentration. The oedema often resolves despite continued hypoalbuminaemia ${ }^{11}{ }^{12}$ during recovery. Leaky cell membranes, ${ }^{13}$ low capillary filtration rates, which appear to be a unique manifestation of kwashiorkor, ${ }^{14}$ and free radicals, which may increase the permeability of capillaries, ${ }^{15}$ could all contribute to the oedema. These concepts are in keeping with the hypothesis of Golden and Ramdath that increased free radical formation and a deficiency of nutrients essential for protective antioxidant function occur, ${ }^{16}$ although the role of free radicals and their scavengers in patients with kwashiorkor remains to be clarified. ${ }^{17}$

Iron bound to transferrin does not readily participate in radical reactions. Transferrin is normally only one third loaded with iron and therefore is an effective antioxidant with an iron binding capacity capable of maintaining the concentration of free iron in plasma at zero. $^{18}$ The bleomycin assay does not detect iron bound to transferrin, lactoferrin ferritin, haemoglobin, or catalase ${ }^{6}$ but is a specific measurement of iron salts which have the potential to catalyse the formation of reactive free radicals. ${ }^{19}$

In previous studies we have shown that BDI was present in 58\% of children with kwashiorkor ${ }^{1}$ and that malondialdehyde (measured as thiobarbituric acid reactive substances), a marker of lipid perioxidation, was raised in these patients. ${ }^{2}$ We have confirmed the findings of others ${ }^{16}$ that serum ferritin is increased, ${ }^{3}$ that stainable iron is present in bone marrow, and that raised concentrations of iron are excreted in the urine of children with kwashiorkor after chelation with desferrioxamine. ${ }^{20}$ These observations suggest that a transient iron overload may be present in children with kwashiorkor.

In conditions of iron overload secondary to haemachromatosis, transferrin loses its antioxidant activity and becomes highly saturated with iron. ${ }^{18}$ The results of our study indicate a comparable situation in patients with kwashiorkor. Plasma concentrations of transferrin were low on admission and were highly saturated at 52 and $72 \%$ in the groups with moderate and severe oedema respectively. After

Table 2 Median and interquartile ranges of plasma BDI, transferrin, transferrin saturation, and albumin in children with moderate or severe oedema of kwashiorkor

\begin{tabular}{llllll}
\hline & Degree of oedema & Admission & 24 hours & Day 10 & Day 30 \\
\hline BDI $(\mu \mathrm{mol} / \mathrm{l})$ & Moderate & $6.75(0.5-15.5)$ & $0(0-1.25)$ & $0(0-0.5)$ & 0 \\
& Severe & $20.5(18.5-21.0)$ & $17.0(13.5-18.5)$ & $0.013(0-0.88)$ & 0 \\
Transferrin $(\mathrm{g} / \mathrm{l})$ & Moderate & $0.62(0.44-1.05)$ & $0.86(0.45-1.21)$ & $1.97(1.88-1.98)$ & $3.24(2.63-3.59)$ \\
& Severe & $0.46(0.39-0.73)$ & $0.42(0.38-0.5)$ & $1.12(1.03-1.77)$ & $2.95(2.87-3.33)$ \\
Transferrin saturation $(\%)$ & Moderate & $52.2(45.0-67.3)$ & $34.2(26.0-49.4)$ & $9.6(7.9-14.5)$ & $14.4(14.0-14.9)$ \\
& Severe & $72.0(60.9-80.9)$ & $64.8(35.2-87.5)$ & $20.2(13.8-38.6)$ & $14.8(8.0-17.5)$ \\
Albumin $(\mathrm{g} / \mathrm{l})$ & Moderate & $17(16-18)$ & ND & $28(27-29)$ & $40(39-44)$ \\
& Severe & $16(13-17)$ & ND & $21(16-24)$ & $37(32-38)$ \\
\hline
\end{tabular}

$\mathrm{ND}=$ not determined 
24 hours of hospitalisation, BDI was still present although the concentration was slightly lower. By day 10 BDI was absent in all except two patients. There was a corresponding increase in transferrin concentrations and a decrease in transferrin saturation over this period as shown in table 1 . By day 10 all the children had lost their oedema. These findings of high concentrations of circulating free iron perhaps account for the observation of McFarlane et al of a grave prognosis for children with extremely low transferrin concentrations. ${ }^{21}$ In a study of 40 patients with kwashiorkor, those who died had a mean serum transferrin value of $0.33 \mu \mathrm{g} / 1$ compared with $1.3 \mu \mathrm{g} / 1$ in those who survived. In our institution mortality from kwashiorkor remains appreciable at approximately $10 \%$ despite intensive care, aggressive treatment of infection, and careful attention to fluid and metabolic balance.

The present study clearly demonstrates higher concentrations of free circulating iron on admission in the severely oedematous than in moderately oedematous patients. Low concentrations of iron binding proteins with raised saturation of transferrin may predispose to free iron and enhanced free radical generation, factors that could contribute to the morbidity and mortality of kwashiorkor. The potential for iron chelation therapy to benefit these children deserves consideration.

We are indebted to the clinical and nursing staff of the paediatric wards for the care of the patients and to Mrs L Heuer for preparation of the manuscript. The study was supported by a grant from the Rita and Phillip Brodie Associateship in grant from

1 Dempster WS, Sive AA, Malan H, Heese H deV. Misplaced iron in kwashiorkor. Eur f Clin Nutr 1995;49:208-21.

2 Sive AA, Subotzky EF, Malan H, Dempster WS, Heese H deV. Red cell antioxidant enzyme concentrations in kwashiorkor and marasmus. Ann Trop Paediatr 1993;13:33-8.
3 Subotzky EF, Heese H deV, Sive AA, Dempster WS, Sacks R, Malan H. Plasma zinc, copper, selenium, ferritin and whole blood manganese concentrations in children with kwashiorkor in the acute stage and during refeeding. Ann Trop Paediatr 1992;12:13-22.

4 Golden MHN. The consequences of protein deficiency in man and its relationship to the features of kwashiorkor. In: Blaxter K, Waterlow JC, eds. Nutritional adaptation in man. London: Applied Science Publishers, 1985:169-87.

5 Gutteridge JMC, Halliwell B. Iron toxicity and oxygen radicals. In: Hershko $\mathrm{C}$, ed. Clinical haematology. Iron chelating therapy. London: Bailliere Tindall, 1989:195-256.

6 Gutteridge JMC, Rowley DA, Halliwell B. Superoxidedependent formation of hydroxyl radicals in the presence of iron salts. Detection of free iron in biological systems using bleomycin-dependent degradation of DNA. Biochem $f$ 1981;199:263-5.

7 Gurney JM. The young child: protein energy malnutrition. In: Jelliffee DB, Jelliffee EFP, eds. Nutrition and growth New York: Plenum Press, 1979:185-216.

8 Gunston G, Burkimsher D, Malan H, Sive AA. Reversible cerebral shrinkage in kwashiorkor: an MRI study. Arch Dis Child 1992;67:818-21.

9 Williams CD. Nutritional diseases of childhood associated with maize diet. Arch Dis Child 1933;8:423-33.

10 Coward WA, Fiorotto $M$. The pathogenesis of oedema in kwashiorkor: the role of plasma proteins. Proc Nutr Soc 1979;38:51-9.

11 Golden MHN, Golden BE, Jackson AA. Albumin and nutritional oedema. Lancet 1980;i:114-6.

12 Waterlow JC. Kwashiorkor revisited: the pathogenesis of oedema in kwashiorkor and its significance. Trans $R$ Soc Trop Med 1984;78:436-41.

3 Patrick J. Oedema in protein energy malnutrition: the role of the sodium pump. Proc Nutr Soc 1979;38:61-8.

14 Richardson D, Iputo J. Effects of kwashiorkor malnutrition on measured capillary filtration rate in the forearm. $A m \mathcal{F}$ Physiol 1992;262:H496-502.

15 Granger ND, Parks DA. Role of oxygen radicals in the pathogenesis of intestinal ischaemia. Physiologist 1983;26: 159-64.

16 Golden MHN, Ramdath D. Free radicals in the pathogenesis of kwashiorkor. Proc Nutr Soc 1987;46:53-68.

17 Kaschula ROC. Malnutrition and intestinal malabsorption. Kaschula ROC. Malnutrition and int
Tropical Pathology 1995;8:985-1030.

18 Gutteridge JMC, Halliwell B. Radical-promoting looselybound iron in biological fluids and the bleomycin assay. Life Chemical Reports 1987;4:113-42.

19 Halliwell B. Superoxide-dependent formation of hydroxyl radicals in the presence of iron chelates: is it a mechanism for hydroxyl radical production in biochemical systems? FEBS Lett 1978;92:321-6.

20 Sive AA, Dempster WS, Rosseau S, Kelly M, Malan H, Heese $\mathrm{H} \mathrm{deV}$. Bone marrow and chelatable iron in patients with protein energy malnutrition. S Afr Med f 1996;86: 1410-3.

21 McFarlane H, Reddy S, Adcock KJ, Adeshina H, Cooke $\mathrm{AR}$, Akene J. Immunity transferrin and survival in AR, Akene J. Immunity transfe
kwashiorkor. BMf 1970;iv:268-70. 